\title{
Global Dryland Ecosystem Programme (Global-DEP): Australasian consultation report
}

\author{
Xiaoming Feng ${ }^{1,2} \cdot$ Mark Stafford-Smith $^{3} \cdot$ Lu Zhang $^{3} \cdot$ Nan Lyu $^{1,2} \cdot$ Yihe Lyu $^{1,2} \cdot$ Bojie Fu $^{1,2} \cdot$ Zhihong Xu $^{4}$
}

Published online: 12 March 2020

(C) Springer-Verlag GmbH Germany, part of Springer Nature 2020

Drylands occupy about $41 \%$ of Earth's land area and are home to more than 2 billion people, at least half of whom are dependent on dryland ecosystem services for their livelihoods and wellbeing. Because drylands are by definition climatically challenged, and because so many peoples' livelihoods depend on managing these challenges, climate and other environmental changes have the potential to impact dryland inhabitants early. Such impacts affect ecosystems and people in but also beyond drylands, for example where people are forced to migrate.

The Global Dryland Ecosystem Programme (Global-DEP) is an initiative to build international cooperation around these concerns. Since 2017, the Global-DEP Interim Scientific Committee, co-chaired by Prof. Bojie Fu and Dr. Mark Stafford Smith and with members from across the world, has been developing a Science Plan with technical support from a Secretariat based in the Chinese Academy of Sciences. Four thematic workgroups and five regional workgroups have also been established between principal investigators from the Chinese Academy of Sciences and their counterparts from the USA, Central Asia, Australia, Africa and other regions, with the aim of consulting widely as to the regional priorities for the Science Plan. Global-DEP aims to provide a platform for global research collaboration on dryland ecosystems that engages global researchers, practitioners and policymakers in

Mark Stafford-Smith

mark.staffordsmith@csiro.com

Zhihong Xu

zhihong.xu@griffith.edu.au

1 State Key Laboratory of Urban and Regional Ecology, Research Center for Eco-Environmental Sciences, Chinese Academy of Sciences, Beijing, China

2 University of Chinese Academy of Sciences, Beijing, China

3 CSIRO Land \& Water, Canberra, ACT, Australia

4 Environmental Futures Research Institute, School of Environment and Science, Griffith University, Nathan, QLD, Australia developing an Action Plan that secures funding for programme implementation. Through an integrative approach of biogeochemistry, ecology and sociology, future efforts should explore the links between the impacts on drylands and the provisioning of services for human livelihoods. Such efforts will enhance the monitoring, assessment and management of global dryland ecosystems and help to deliver the sustainable development goals in dryland regions.

One of the regional consultations being undertaken by Global-DEP was convened in Canberra, Australia, on 5 September 2019, and is the subject of this report.

Around $87 \%$ of Australia $\left(\sim 6.7 \mathrm{~m} \mathrm{~km}^{2}\right)$ is classified as drylands, about a tenth of which is dry subhumid and the rest arid or semi-arid; there are no hyper-arid areas in Australia, and this represents almost all the drylands in Australasia (FAO 2019). Around $80 \%$ of Australia is classified as rangelands, where land use is dominated by extensive grazing, conservation lands, Aboriginal homelands, mining and tourism; this $80 \%$ by area is home to only $2 \%(\sim 400,000$ people $)$ of the Australian population, so is generally very lightly settled, with a much higher proportion of Aboriginal people than the country as a whole (28\% compared to $2.8 \%$ nationally) (see details in Foran et al. 2019). Grazing of sheep and cattle ( $\sim .5 \mathrm{~m}$ and $8.6 \mathrm{~m}$ respectively in 2016) is the dominant land use, occurring on $\sim 55 \%$ of the rangelands area, $\sim 10 \%$ is in the conservation estate and $\sim 34 \%$ in some form of exclusive indigenous title. Foran et al. (2019) highlight 5 key issues for the future of the rangelands part of the Australian drylands socialecological system: ensuring a social licence to operate across various uses; acknowledging and supporting a younger, more Indigenous population; implementing positive aspects of technological innovation; halting capital and governance leakages; building human capacity. This paper illustrates the degree to which Australian rangelands' research has increasingly emphasised a deep interdisciplinary consideration of the challenges drylands face, linking local management to national policies and global markets. The small research community coupled with the diversity and huge area of Australian 
rangelands has forced researchers to think about how to classify systems so that advice can be given appropriately.

Dryland cropping occurs on around $5 \%\left(0.38 \mathrm{~m} \mathrm{~km}^{2}\right)$ of Australia, most of which is rainfed but up to tenth of this may be irrigated in some or all years. The consultation reported here was undertaken in the wings of the Australian Rangelands Society 2019 Conference, so there were few participants representing the dryland cropping issues. In fact, Australia also has a long history of innovation in this context, from early 'stump-jump ploughs', to recent crop and pasture management (e.g. low and no-till approaches), water use and governance and dryland crop cultivar development, as well as management of emergent environmental issues such as dryland salinity. Dryland cropping continues to face new challenges such as those arising directly and indirectly from climate change.

The Australian consultation for Global-DEP gathered nearly 28 participants (see Fig. 1) from 20 research institutes and universities around Australia, including 3 members of the Global-DEP Scientific Committee. The consultation addressed five areas of potential research in Australia, as reported below:

\section{Capturing the diversity of social-ecological conditions of drylands, from an Australasian perspective}

As noted, Australian researchers are attuned to the need to classify systems due to the diversity of drylands in Australia, even though this diversity (particularly on the social side) is relatively small compared to drylands globally. Dryland attributes that were highlighted for consideration included different land tenure and management policies, cultural attributes and social perceptions, conflicts in values, levels of education and training among farmers and the nature of livestock marketing including fair trade value chains. Specific variables to help classify dryland types in Australia included climate zones (including variability and seasonality), land use types and key stressor variables (e.g. grazing pressure, temperature extremes, human presence). The Interim Biogeographic Regionalisation for Australia (IBRA) ecosystem classification was noted as a key Australian resource. Key direction to consider for the future included 'carbon farming' for carbon capture and the co-benefits of controlling soil erosion, promoting environmental awareness and recognizing that subsidies by themselves are not a good solution.

\section{Drivers and types of ecosystem shifts and tipping points, from an Australasian perspective}

Drivers highlighted in Australia were land-use change, feral animals (both grazing and predator) and invasive plants (e.g. 'woody weeds', but also grasses such as buffel grass), clearing, total grazing pressure, increasing extreme climate events and other climate changes, export demand and market fluctuations, carbon farming, changes in labour and capital, land values, technological disruption (e.g. from ploughing to chemicals, communications), population and demographics (including ageing), loss of knowledge, transfer of knowledge

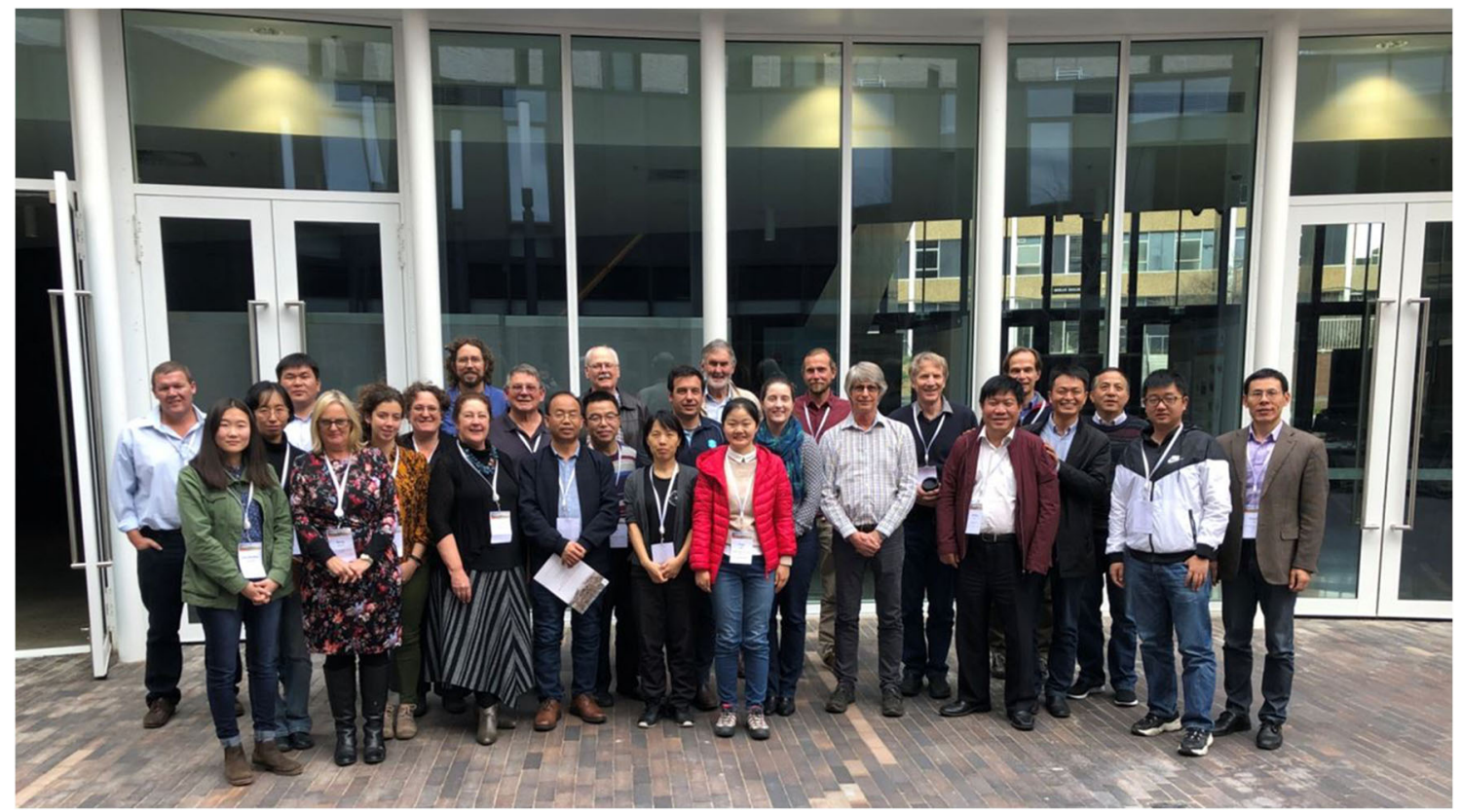

Fig. 1 Participants of the Global-DEP Australasian Consultation, Canberra, 5 September 2019 
and cultural loss/respect for indigenous knowledge. Some of these changes are enabling (e.g. technology), others are barriers.

A key issue highlighted by participants is that the stressors are often co-occurring and interacting-e.g. market change, drought, rabbit control and fire management. These can also intersect with changing policies. In addition, many of these issues do not operate homogeneously across Australia. Some key differentiated pressures and changes include, for example an emphasis on clearing and land-use change in the states of New South Wales and Queensland, linked to erosion and salinisation in places as well as 'woody weed thickening' in these states and Western Australia; whilst in the Kimberley region of Western Australia as well as in western South Australia, moves to prioritise cultural landscapes and cultural practices such as fire management are important. Also notable is that rainfall has generally decreased in southern rangelands and if anything, increased in the north. The competition for water is increasing especially around wetlands.

Participants also noted the opportunities to use existing networks and infrastructure and to identify gaps in research cover either sectorally or geographically; some example activities are DroughtNet, Aridity gradient thinking and NutrientNet.

\section{Options for regional case studies in Australasia}

Participants identified an extended list of possible case studies which could be followed up, but which are summarised briefly here:

- Institutional activities - state government activities in monitoring (e.g. the WARMS system in Western Australia), remote sensing (in Queensland), climate (University of Southern Queensland), social well-being survey (University of Canberra), capacity building (Rangelands Australia, University of Queensland) and cultural science (New South Wales Office of Environment and Heritage).

- Community networks and other less formal organisations-Australian Landcare Network, distance education systems (e.g. School of the Air), Future Beef website.

- Suggested case study research activities - groundwaterdependent ecosystems, drought management research, ecosystem restoration (to what and over what time?), role of livestock in restoration, carbon farming, productivity in the beef industry (e.g. breeder herd efficiency, weaning rates, effects of stocking rate), comparing regions with declining vs increasing populations, comparing regions with different combinations of landholder age, tenure and regulation, effects of land tenure and rural poverty, strategies for diversification and intensification.
- Products - 'ABCD' Land Condition Framework for the Burdekin region of Queensland.

\section{What stakeholders to engage with and why, from an Australasian perspective}

A range of important stakeholder groups was identified, including government and related institutions making decisions about land use planning and management, rangeland users whose livelihoods depend on dryland resources, regional bodies, Indigenous groups, tourism operators and perhaps mining interests.

Participants discussed how some challenges may be fairly unique to Australia, driven by the specific characteristics of its drylands, including its governance structure (rangelands across 5 state jurisdictions, though all in one country), a very low population in general, diverse business structures of farming enterprises in drylands, competing land-use interests (mining, oil and gas, renewable energy sources, carbon farming, defense use, even astronomy), the considerable extent of fireprone landscapes and especially high levels of climate variability and now climate change.

\section{Key areas for drylands research in Australia}

Given these special challenges, some key areas for research were identified that the Global-DEP plan might need to be able to encompass, including the following:

- Carbon management:

- Measuring and reducing the carbon footprint of dryland agricultural industries.

- How to fit carbon neutrality and carbon farming into enterprise structures?

- Who will pay for carbon neutrality? Through what policy instruments?

- Valuing ecological services:

- Social-economic survey of users to understand how they value ecosystem services.

- Development of better decision-making processes to cope with pervasive uncertainty:

- Meteorological research to provide better predictive capacity at a 2-5-year timescale and regional spatial scale (i.e. as early warning system). 
- Identification of critical thresholds that would shift ecosystems to a different state, and early warning for these.

- Research structural adjustment (loss of people, loss of services) from landscapes:

- Research into sustainability of support for indigenous people in remote areas.

- How to engage/invite youth interest in dryland issues?

- Research into cheaper communications technologies across drylands.

- Better management of grazing pressure and water in dryland areas:

- Greater water use efficiency.

- When to adjust stock numbers?

In conclusion, these issues provide a time capsule of concerns from Australian rangelands researchers that can be taken account of in the design of the Global-DEP Science Plan, in conjunction with comparable inputs from other regional consultations around the world. The goal is to launch the draft plan for public feedback during 2020, and launch Global-DEP as an active international collaborative programme by 2021 .

Acknowledgements This consultation was supported by the International Partnership Program of Chinese Academy of Sciences (121311KYSB20170004).

\section{References}

FAO (2019) Trees, forests and land use in drylands: the first global assessment - full report. FAO Forestry Paper No. 184, Rome

Foran B, Stafford Smith M, Burnside D, Andrew M, Blesing D, Forrest K, Taylor J (2019) Australian rangeland futures: time now for systemic responses to interconnected challenges. Rangel J 41(3):271292. https://doi.org/10.1071/rj18105

Publisher's note Springer Nature remains neutral with regard to jurisdictional claims in published maps and institutional affiliations. 